\title{
Pulmonary alveolar proteinosis in Korea: analysis of prevalence and incidence via a nationwide population-based study
}

\author{
Hee-young Yoon ${ }^{1,2}$, Ji Hyeon $\mathrm{Kim}^{2}$, Ye-Jee $\mathrm{Kim}^{3}$ and Jin Woo Song ${ }^{2^{*}}$ (D
}

\begin{abstract}
Background: Pulmonary alveolar proteinosis (PAP) is a very rare lung disease and its prevalence and incidence remain unclear. The prevalence and incidence of PAP were investigated by using nationwide claims data from the Korean Health Insurance Review and Assessment service.

Methods: Data were extracted for adults who visited any secondary or tertiary medical institute between 2010 and 2016 with the PAP-related Korean Classification of Disease, 7th edition code J84.0 and the Rare Intractable Disease exempted calculation code V222. To robust case definition, a narrow case definition was made when all following factors were met: 1) more than two PAP-coded visits within 1 year of the first claim, and 2) more than one claim for both chest computed tomography and diagnostic procedures (bronchoscopy or surgical lung biopsy) within 90 days before or after the first claim.
\end{abstract}

Results: A total of 182 patients (narrow, $n=82$ ) with PAP-related codes were identified from 2010 to 2016 and 89 new patients (narrow, $n=66$ ) visited medical institutes between 2012 and 2015. The prevalence of PAP was 4.44 (narrow: 2.27) per $10^{6}$ population, with a peak age of 60-69 years. The incidence of PAP was 0.56 (narrow: 0.41) per $10^{6}$ population at risk, with a peak age of 50-59 years. Among incident cases, the male-to-female ratio was 1.52 and about two-thirds had comorbidities, dyslipidaemia being the most common.

Conclusions: The prevalence and incidence of PAP in Korea are low, similar to those in other countries; however, Korean patients with PAP are characterized by older diagnostic age and a lower male-to-female ratio.

Keywords: Epidemiology, Insurance claim review, Health care survey, National Health Programs, Rare diseases

\section{Background}

Pulmonary alveolar proteinosis (PAP) is an extremely rare disease characterized by progressive accumulation of surfactant in the alveoli. PAP can affect all ages and sexes and shows diverse clinical courses, ranging from spontaneous resolution to respiratory insufficiency $[1,2]$. Based on several case reports and series, the peak incidence of PAP is between 30 and 40 years and it predominantly occurs in men [2-10]. In previous studies, the prevalence of PAP was estimated to be 3.7-6.9 per $10^{6}$ population and incidence was estimated to be less than 1 person per $10^{6}$ population at risk $[2-4,11]$; however,

\footnotetext{
* Correspondence: jwsongasan@gmail.com

${ }^{2}$ Department of Pulmonary and Critical Care Medicine, Asan Medical Center, University of Ulsan College of Medicine, 88 Olympic-Ro 43-Gil, Songpa-Gu, Seoul 05505, Republic of Korea

Full list of author information is available at the end of the article
}

there are still limited data on the prevalence and incidence of PAP, especially in the Asian population.

In Asian countries including Korea, PAP was reported to be more prevalent in men, but the male-to-female ratio was relatively lower when compared with that of Western countries (1.3-2.1 [Asian] vs. 2.4-4.0 [Western]) [4, 5, 8, $10,12,13]$. In addition, the age at diagnosis of Asian patients was usually higher (mean age: $47.5-52$ vs. 34-49 years) $[4,5,8,10,12,13]$. These results may reflect the genetic and environmental differences of Asian patients with PAP; however, these previous studies in Asia may have biased results since they included only selected patients who visited 10-15 referral medical institutes or those enrolled in the national PAP registry $[4,12,13]$. Therefore, in order to overcome these limitations,

(c) The Author(s). 2020 Open Access This article is distributed under the terms of the Creative Commons Attribution 4.0 International License (http://creativecommons.org/licenses/by/4.0/), which permits unrestricted use, distribution, and reproduction in any medium, provided you give appropriate credit to the original author(s) and the source, provide a link to the Creative Commons license, and indicate if changes were made. The Creative Commons Public Domain Dedication waiver (http://creativecommons.org/publicdomain/zero/1.0/) applies to the data made available in this article, unless otherwise stated. 
epidemiological studies based on entire populations are needed for rare diseases such as PAP.

More than $97 \%$ of the Korean population is covered by the National Health Insurance (NHI) system, which is a nationwide mandatory insurance scheme provided by the Korean government. Thus, claims data are appropriate for assessing the epidemiology of rare diseases in the whole population. The aim of this study was to estimate the prevalence and incidence of PAP in Korea by using the nationwide claims data.

\section{Materials}

\section{Data source}

From the Health Insurance and Review Agency (HIRA) database between January 2010 and December 2016, deidentified health claims data were obtained. This agency covers all health claims from the Korean NHI scheme and other available medical assistance programs (i.e., the Medical Assistance Program and Veterans Affairs Schemes) in South Korea. HIRA electronically collects the health claims data from medical institutions and stored data in the HIRA claims database. HIRA database includes all healthcare utilization information from inpatients and outpatients, including patient demographics, diagnosis, diagnostic procedures, and prescribed medication. The seventh edition of the Korean Classification of Disease (KCD-7), and the modification of the 10th revision of the International Classification of Disease and Related Health Problems, (ICD-10) were the sources for diagnostic codes (Additional file 1: Table S1).

Since 2010, PAP was added to the Rare Intractable Disease (RID) registration program, an NHI scheme initiated in 2006 with a current total of 167 rare intractable diseases. For patients to be registered into the RID program, a physician must confirm the diagnosis of PAP using the NHI criteria. The registered patients are then provided a co-payment reduction of $90 \%$ [14-17]. It is important to diagnose PAP correctly to meet all the NHI criteria, because medical institutions could not charge the NHI for medical expenses if a presumed diagnosis of PAP did not meet all the NHI criteria. Thus, all physicians involved strictly determined whether each patient qualified for registration in the RID system according to the standard NHI diagnostic criteria. Therefore, it is assumed that an accurate diagnosis must have been made at the time of RID registration. Also, previous studies have used the RID system to evaluate the prevalence and incidence of other rare diseases in Korea [14, 15, 17]. Following registration, both PAP-related KCD-7 (J84.0) and RID codes (V222) were listed in PAP-related claims.

\section{Study population}

All adult individuals ( $\geq 20$ years) who visited the secondary or tertiary care medical institutions with the PAP- related KCD-7 code J84.0 as a diagnosis and the RID exempted calculation code V222 from 2010 to 2016 were included in the study. The NHI criteria required for PAP registration in the RID program are as follows: 1) compatible chest computed tomography findings with PAP and 2) bronchoalveolar lavage fluid or histopathologic findings compatible with PAP.

Since our study defined PAP cases structurally using claim data, narrow case definition was madden, to reduce possibility of overestimation or uncertainty of diagnosis. Following were the conditions used for narrow case definition; 1) at least two visits with a PAP-related code within a year of the first claim, and 2) claims of both chest computed tomography (CT) and diagnostic procedures (either bronchoscopy [BFS] or surgical lung biopsy) within 90 days before or after the first claim. The study was approved by the Institutional Review Board of Asan Medical Centre (2017-1190).

\section{Statistical analyses}

For estimating prevalence, the patients identified with PAP during the study period were included in the prevalence estimates. Grounded on prevalent cases for 2010 and 2011, newly diagnosed patients from 2012 to 2016 were cumulatively added every year. The prevalence was calculated as follows: the number of total cases identified with PAP divided by the total population of South Korea for the year 2016. The Korean Statistical Information Service (http://kosis.kr) provided the 2016 population estimate. For the estimation of incidence, the date of the earliest claim of PAP was defined as the index date and the patient was regarded to be an incident case in that year. A clearance period was established by excluding cases identified in the first 2 years (2010-2011) to remove any potential pre-existing cases of PAP. The cases identified in 2016 were also excluded due to insufficient follow-up data. The annual incidence rate from 2012 to 2015 was calculated as follows: the number of newly identified cases in a corresponding year divided by the population at risk. The population at risk was calculated by removing the identified pre-existing cases of PAP from the mid-year population.

To compare the incidence rates over time, a standardized incidence for the Korean population in 2015 served as a reference, using direct standardization. The 95\% confidence interval (CI) of prevalence and incidence rates was calculated using a Poisson distribution. For the newly diagnosed PAP cases, the age, sex, other accompanying diagnostic codes (comorbidities), and codes for diagnostic tests were analysed. The claims data on the diagnostic methods used were collected for 90 days before and after the first vist and the data on accompanying diseases were collected after the first visit. The SAS Enterprise Guide software (version 6.1, SAS Institute, 
Inc., Cary, NC, USA) was used to perform all statistical analyses.

\section{Results}

\section{Prevalence}

A total 182 prevalent cases (males: 119, females: 63) were identified from 2010 to 2016 (Fig. 1). The 7-year prevalence was 4.44 per $10^{6}$ people (95\% CI: $3.82-5.14$ ) in the whole population, 5.87 (95\% CI: 4.86-7.03) in men and 3.05 (95\% CI: 2.34-3.90) in women. Using the narrow case definition, 92 cases (males: 60, females: 32 ) were identified from 2010 to 2015 (Fig. 1) and the 7year prevalence by the narrow definition was 2.27 (95\% CI: $1.83-2.78)$ per $10^{6}$ people and that in men and women was 2.99 (95\% CI: 2.28-3.85) and 1.59 (95\% CI: $1.07-2.21$ ) per $10^{6}$ people, respectively (Additional file 2 : Table S2).

The highest prevalence was observed in individuals aged $60-69$ years $\left(8.35\right.$ per $10^{6}$ people), followed by individuals aged $>70$ (7.83 per $10^{6}$ people) (Additional file 2 : Table S2). The peak prevalence in men was observed in individuals aged 60-69 years, whereas that in women was observed in individuals aged $>70$ years. Using the narrow case definition, the peak prevalence age in the whole population, men, or women was 50-59 years, followed by $60-69$ years (Fig. 2b).

\section{Incidence}

Eighty-nine patients (males: 57, females: 32 ) were identified as incident cases between 2012 and 2015. The incidence rate was 0.56 (95\% CI: $0.45-0.69)$ per $10^{6}$ population at risk in the whole population, and the incidence rates in men and women were 0.72 (95\% CI: $0.55-0.94)$ and 0.40 (95\% CI: $0.27-0.56)$ per $10^{6}$ population at risk, respectively (Additional file 3: Table S3). Using the narrow definition, the incidence rate was 0.41 (95\% CI: $0.32-0.53$ ) per $10^{6}$ population at risk in the whole population, 0.58 (95\% CI: $0.43-0.78$ ) in men, and 0.25 (95\% CI: 0.15-0.38) in women.

The age-specific incidence rate in the whole population and in both sexes was highest among 50-59 years (Fig. 3a; Additional file 3: Table S3). Using the narrow case definition, the peak incident rates in the total population and in men were highest in individuals aged 5059 years, whereas that in women was highest in individuals aged $60-69$ years (Fig. 3b).

\section{Changes in the annual incidence rates}

The age- and sex-standardized annual incidence rates were similar through the study period from 0.56 (95\% CI: $0.35-0.84)$ per $10^{6}$ population at risk in 2012 to 0.52 (95\% CI: $0.32-0.79)$ per $10^{6}$ population at risk in 2015 (Fig. 4a). Both sexes also showed similar findings. The

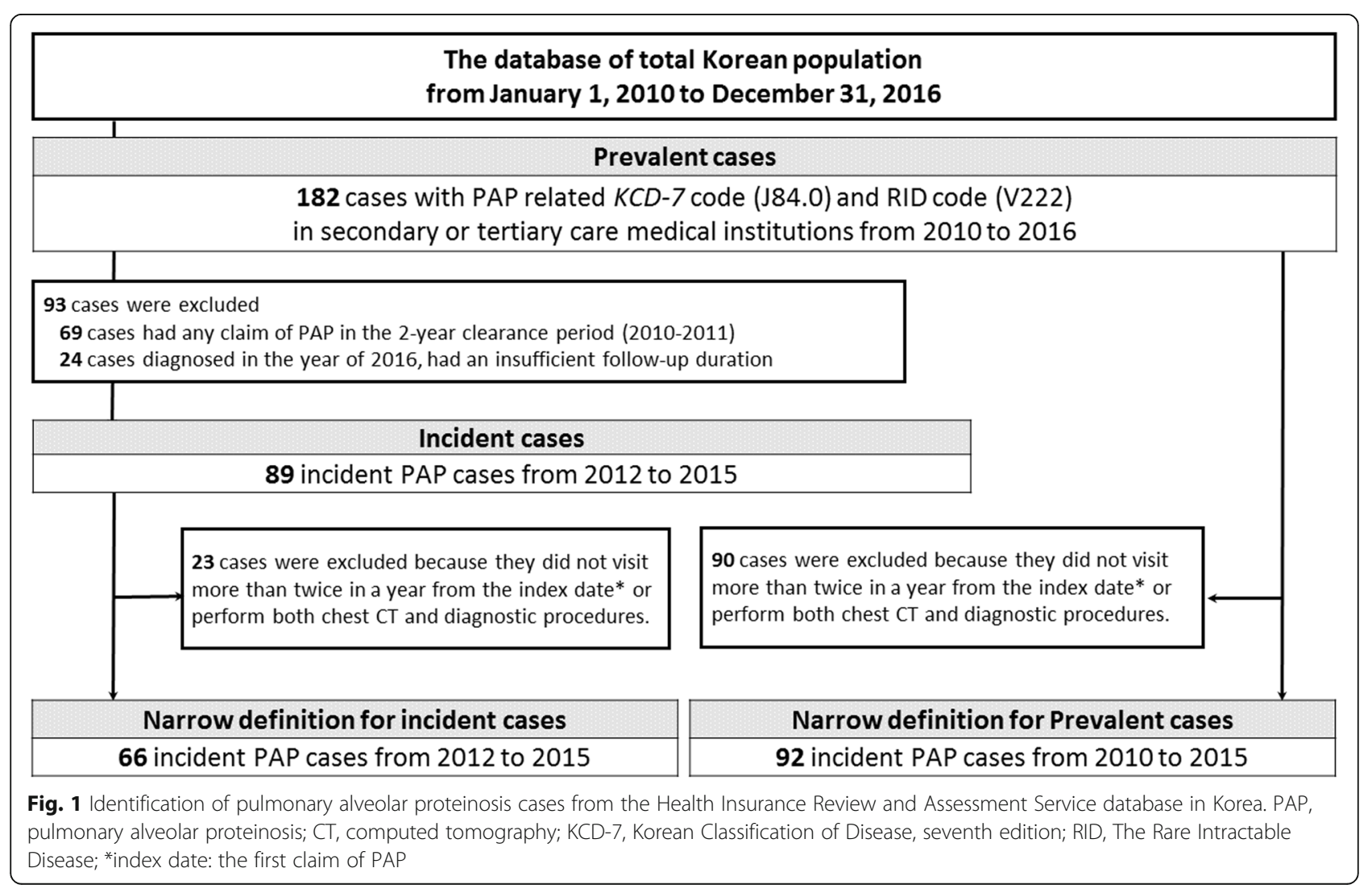



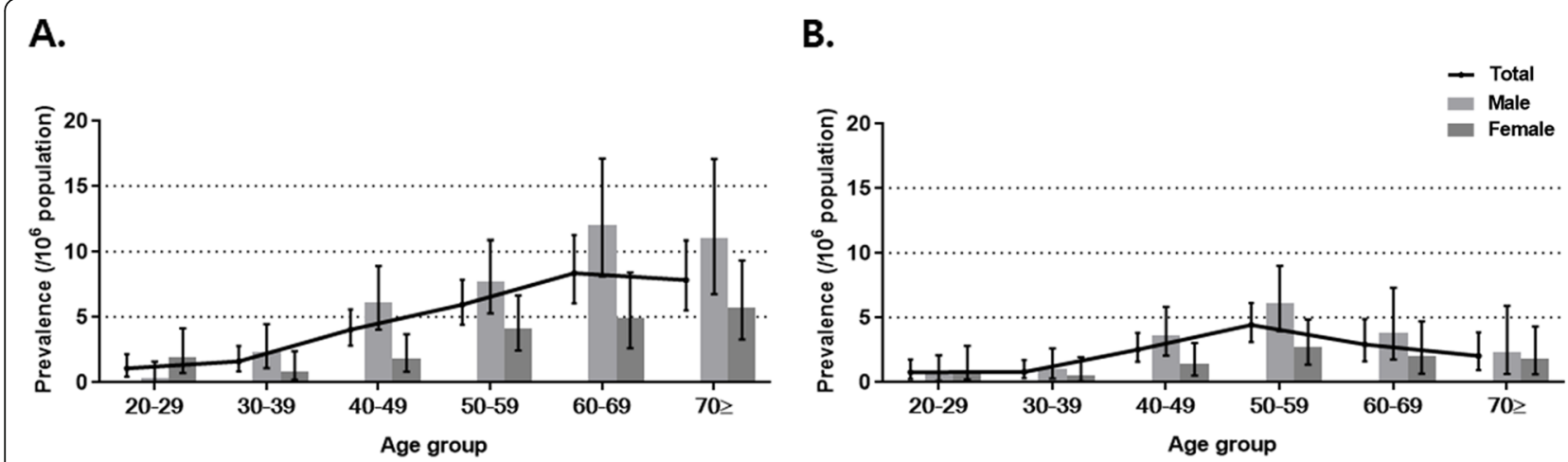

Fig. 2 Age- and sex-stratified prevalence of pulmonary alveolar proteinosis a Prevalence from 2010 to $2016 \mathbf{b}$ Prevalence of PAP from 2010 to 2015 based on the narrow definition. Data presented as the mean $\pm 95 \%$ confidence interval

standardized annual incidence rates in men were 0.78 (95\% CI: $0.44-1.27$ ) per $10^{6}$ population at risk in 2012 and $0.60(95 \%$ CI: $0.31-1.05)$ per $10^{6}$ population at risk in 2015, and those in women were 0.35 (95\% CI: 0.140.70 ] per $10^{6}$ population at risk in 2012 and $0.44(95 \%$ CI: $0.20-0.83)$ per $10^{6}$ population at risk in 2015. The age- and sex-standardized annual incidence rates according to the narrow definition were also stable between 2012 and 2015 in all patients (from 0.45 [95\% CI: $0.26-0.70$ ] to 0.39 [95\% CI: $0.23-0.64$ ] per $10^{6}$ population at risk), in men (from 0.67 [95\% CI: 0.35-1.11] to 0.46 [95\% CI: $0.21-0.85]$ per $10^{6}$ population at risk), and in women (from 0.25 [95\% CI: $0.08-0.57]$ to 0.29 [95\% CI: 0.11-0.64] per $10^{6}$ population at risk) (Fig. $4 \mathrm{~b}$ ).

\section{Demographics and diagnostic methods in incident cases} The mean age of incident cases was $50.8 \pm 13.4$ years (men: $52.1 \pm 11.8$ years, women: $48.4 \pm 15.8$ years). The male-to-female ratio of incident cases was 1.82 and peaked at age $40-49$ years. Of the incident cases, 92.1 and $70.8 \%$ had claims of the chest CT and BFS for 90 days before and after the first visit, respectively (Table 1).
Surgical lung biopsy was performed in $34.8 \%$ of the incident cases.

\section{Comorbidities of incident cases}

The most common accompanying diagnostic code encountered in the incident cases was dyslipidaemia (E78, $60.7 \%$ ), followed by diabetes mellitus (E10-14, 40.5\%), and hypertension (I10-15, 40.5\%) (Table 2). Among respiratory comorbidities, chronic obstructive pulmonary disease (COPD, J44, 23.6\%) was the most common, followed by tuberculosis (A15-19, 5.6\%), and nontuberculous mycobacteria (A31.9, 1.1\%). (Table 2).

\section{Discussion}

This study is the first population-based study assessing the prevalence and incidence of PAP in Korea using data from a nationwide medical claims database. The prevalence and incidence of PAP in Korea were low, similar to those of other countries, but characterized by older diagnostic age and lower male to female ratio when compared to other countries. The annual incidence rate

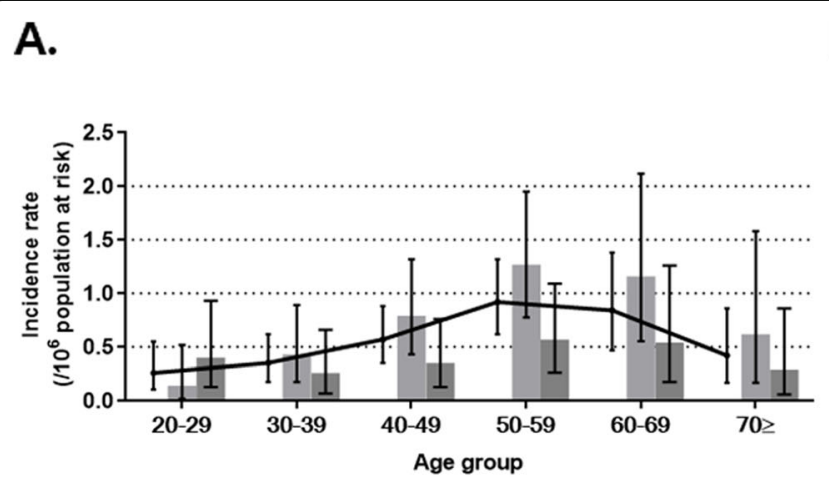

B.

Fig. 3 Age- and sex-stratified incidence rates of pulmonary alveolar proteinosis a Incidence rate from 2012 to 2015 b Incidence rate from 2012 to 2015 based on the narrow definition. Data presented as the mean $\pm 95 \%$ confidence interval 

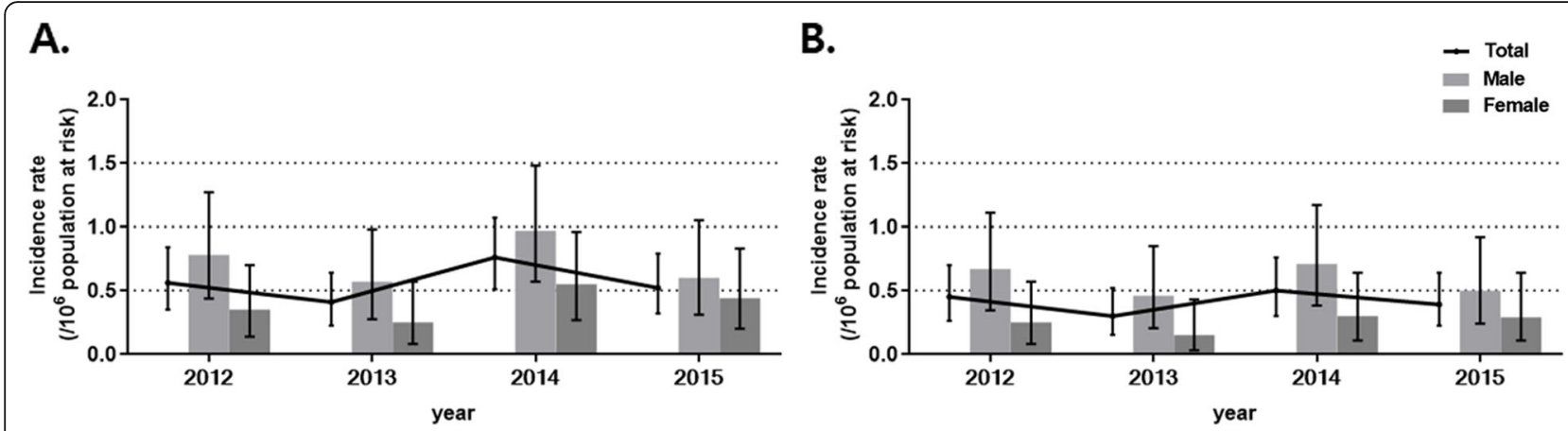

Fig. 4 Age- and sex-standardized annual incidence rate of pulmonary alveolar proteinosis a Incidence rate from 2012 to 2015 b Incidence rate from 2012 to 2015 based on the narrow definition. Data presented as the mean $\pm 95 \%$ confidence interval

was steady during the study period and middle-aged men showed the highest risk.

Our results showed a low prevalence of PAP in Korea (4.44 per $10^{6}$ people from 2010 to 2016), similar to that in Japan $[4,11]$. Inoue $Y$. et al., using national cohort data from 9 primary clinical research centres in Japan, reported that the prevalence of autoimmune PAP was 6.2 per $10^{6}$ population between 1999 and 2006 [4]. The results from Western countries are also compatible with our findings. Ben-Dov I. et al., based on the results from a nationwide survey, showed that the prevalence of PAP in Israel from 1976 to 1998 was 3.7 per $10^{6}$ population [3]. In the study using the health insurance claims data covering approximately 30 million people in the United States, the prevalence of PAP in the United States was reported as 6.9 per $10^{6}$ population between 2008 and 2012 [11]. In addition, the incidence rate of PAP in our study (0.56 per $10^{6}$ population at risk) was similar to that in other countries (0.49 [Japan], 0.36 [Israel]) [3, 4], suggesting that the racial differences of the epidemiology of PAP are not large. However, the demographic features of incident cases in our study showed different results; the mean diagnostic age of this study was higher (50.8 vs. 34-49 years), and the male to female ratio was lower (1.8 vs. 2.4-4.1) than the results of Western countries [5, $10,18,19]$. The study in Japan, however, showed similar findings to our results; the mean diagnostic age was 51 years and the male to female ratio was 2.1 [4]. These

Table 1 Methods used for diagnosing incident pulmonary alveolar proteinosis cases

\begin{tabular}{ll}
\hline Diagnostic methods & $\mathrm{N}(\%)$ \\
\hline Chest computed tomography & $82(92.1)$ \\
Bronchoscopy & $63(70.8)$ \\
Bronchoalveolar lavage & $56(62.9)$ \\
Surgical lung biopsy & $31(34.8)$ \\
\hline
\end{tabular}

Data are presented as total number (\%)

$\mathrm{N}$, total number results suggest that ethnicity may have an impact on the demographic features of PAP.

The age at diagnosis of PAP in our study was similar to that in previous Korean studies [12, 13]. Byun et al., using a cohort of 38 Korean patients who were diagnosed with PAP in 10 secondary and tertiary referral hospitals between 1993 and 2007, showed that the median diagnostic age of PAP was 52 years [12]. Hwang et al., using a cohort of 78 PAP patients diagnosed between 1993 and 2014, also reported similar results (median: 47.5 years, interquartile range: $42.5-59$ years) [13]. However, another study, using a cohort with 12 PAP patients diagnosed between 1987 and 1998, showed a younger diagnostic age (median: 43.5 years, interquartile range: 33.0-51.5) [20] when compared with the previously mentioned recent studies $[12,13]$. These findings might be attributed to the increase of the aging population in Korea; the proportion of the elderly ( $\geq 65$ years) increased from $7.2 \%$ in 2000 to 13.8\% in 2017 (Statistics Korea, http://kostat.go.kr/). In addition, since 2007, the Korean government has been offering regular health check-ups, including a chest $\mathrm{x}$-ray every 2 years to all Koreans $>40$ years of age; therefore, PAP patients $>40$ years of age are more readily detected. This could explain the late diagnostic age of PAP observed in our current study. Recent prevalence of PAP in United States between 2008 and 2012 peaked at over 75 years followed by the aged $65-74$ years also supports the global aging of PAP patients [11].

In this study, the patients diagnosed with PAP commonly had accompanied dyslipidaemia (60.7\%) and diabetes $(40.5 \%)$. In the Korean population, the prevalence of hypercholesterinaemia, hypertriglyceridemia, and diabetes were reported to be $19.9,17.2$, and $11.3 \%$, respectively in 2016, suggesting an increased prevalence of metabolic disorders in Korean patients with PAP when compared with the general population. Previous studies support our findings; in a study involving non-obese and non-diabetic PAP patients $(n=33)$, Tian et al., 
Table 2 Accompanying diagnostic codes in incident pulmonary alveolar proteinosis cases after registration

\begin{tabular}{llll}
\hline & Total & Male & Female \\
\hline Dyslipidaemia (E78) & $54(60.7)$ & $38(66.7)$ & $16(50.0)$ \\
Diabetes mellitus (E10-14) & $36(40.5)$ & $26(45.6)$ & $10(31.3)$ \\
Hypertension (I10-15) & $36(40.5)$ & $24(42.1)$ & $12(37.5)$ \\
Chronic obstructive pulmonary disease (J44) & $21(23.6)$ & $17(29.8)$ & $4(12.5)$ \\
Ischaemic heart disease (I20-25) & $11(12.4)$ & $9(15.8)$ & $2(6.3)$ \\
Malignancy (C00-97) & $9(10.1)$ & $4(7.0)$ & $5(15.6)$ \\
Tuberculosis (A15-19) & $5(5.6)$ & $4(7.0)$ & $1(3.1)$ \\
Non-tuberculous mycobacteria (A31.9) & $1(1.1)$ & $3(5.3)$ & $0(0.0)$ \\
Arrhythmia (I47-49) & $4(4.5)$ & $2(3.5)$ & $1(3.1)$ \\
Renal failure (N17-19) & $3(3.4)$ & $1(1.8)$ & $0(0.0)$ \\
Asbestosis (J61) & $1(1.1)$ &
\end{tabular}

Data are presented as number (\%)

demonstrated increased triglyceride levels (median: $192.0 \mathrm{mg} / \mathrm{dl}$ vs. $119.6 \mathrm{mg} / \mathrm{dl}, p<0.05)$ and reduced highdensity lipoprotein cholesterol levels $(42.5 \mathrm{mg} / \mathrm{dl}$ vs. 51.4 $\mathrm{mg} / \mathrm{dl}, p<0.01)$ when compared with blood pressurematched healthy controls $(n=157)$ [21]. This finding might be linked to the cholesterol-lowering effect of GM-CSF by promoting macrophage functions in lipid metabolism [22]. GM-CSF (Csf2) knockout (Csf2-/-) and Csf2rb gene-deficient (Csf2rb-/-) mice showed surfactant-containing macrophages with excessive accumulation of cholesterol ester-rich lipid-droplets [23]. McCarthy et al., in a study using the claims data, also reported that PAP patients had a higher rate of diabetes (26.9\% vs. $13.4 \%$ ) than the US general population [11]. The insulin resistance observed in these diabetics could be attributed to excessive lipid metabolites or cytokines inhibiting insulin signal $[24,25]$.

In our PAP patients, mycobacterial infection was accompanied by about $5 \%$. Several studies reported the association between tuberculosis (TB) and PAP [26-29]. Zhang et al. reported that TB infection was identified in $44 \%$ of secondary PAP patients $(n=9)$ [26]. Some coexisting cases of PAP and TB have also been reported [2729]. In the experimental study using in vivo model, GMCSF production inhibited mycobacterial growth by mediating invariant natural killer $\mathrm{T}$ cells [30] and in other study, GM-CSF deficient mice fail to control mycobacterial infection due to the reduced lymphocytes recruitments and $\mathrm{T}$ helper cell type 1 response [31]. No specific associations between PAPs and other accompanying diseases (COPD, hypertension, ischemic heart disease)) have been reported, however, clinical characteristics of our incidence cases (the predominance of middle aged-men) may contribute to the coexistence of both diseases.

This study had an increased proportion of subjects who underwent diagnostic bronchoscopy $(70.8 \%$ vs.
41.7-83.3\%) when compared with previous studies [12, $13,20]$; however, the number of subjects who underwent surgical lung biopsy decreased (34.8\% vs. $42.0-58.3 \%$ ). In a review study based on patients with PAP between 1958 and 1988, surgical lung biopsy (71\%) was the main diagnostic tool, while the proportion of bronchoscopy (10\%) for diagnosis was low [2]. However, compared with this earlier study [2], recent studies showed relatively high rates of bronchoscopy (56-97\% [recent] vs. $10 \%$ [earlier]) and low rates of surgical lung biopsy (6$34 \%$ vs. $71 \%$ ) for PAP diagnosis $[4,18,19]$. These results collectively suggest that non-invasive tests are used more actively for the diagnosis of PAP due to increased experience [32].

Several limitations must be considered. Firstly, PAP cases were defined by using diagnostic codes from a national insurance claims database. Since this database did not provide information for personal identification to researchers due to the Korean Personal Information Protection Act, validation through medical chart review was not possible for the diagnosis of PAP cases. Consequently, this lack of validation may have led to an overestimation of the prevalence and incidence rates. To compensate for this shortcoming, the RID registration system, which demanded the subject to satisfy the universal diagnostic criteria for registration and to be reviewed by the medical institutions before submission to the NHI system, wss used. To calculate more accurate the incidence and prevalence of PAP, we also used the narrow definition of PAP. Secondly, our study only included the PAP patients who visited the secondary or tertiary medical institutes. This inclusion criterion might have led to selection bias in that only severe PAP cases were included. However, due to its rarity, it is unlikely that a diagnosis of PAP was made at primary medical institutions. Even if such diagnoses were made, their accuracy would have been a cause of concern. Thus, it was 
appropriate to exclude patients diagnosed at these primary medical institutions. Despite these limitations, our study yielded unbiased results from the entire population.

\section{Conclusion}

Our results suggest that the epidemiology of PAP in Korea estimated using the national insurance claims data is similar to that in other countries; however, the age at diagnosis is higher and the male-to-female ratio is lower when compared with those in Western countries.

\section{Supplementary information}

Supplementary information accompanies this paper at https://doi.org/10 1186/s12890-020-1074-5.

Additional file 1: Table S1. Matching diagnostic codes between the KCD-7 and ICD-10 classifications.

Additional file 2: Table S2. Number of patients with pulmonary alveolar proteinosis and prevalence (per $10^{6}$ population) in Korea from 2010 to 2016

Additional file 3: Table S3. Number of patients with pulmonary alveolar proteinosis and incidence rate (per $10^{6}$ population at risk) in Korea from 2012 to 2015 .

\section{Abbreviations}

BFS: Bronchoscopy; Cl: Confidence interval; CT: Computed tomography; HIRA: Health Insurance and Review Agency; KCD: Korean Classification of Disease; NHI: National Health Insurance; PAP: Pulmonary alveolar proteinosis; RID: Rare Intractable Disease+

\section{Acknowledgments}

We thank the Korean Health Insurance Review and Assessment Service and the National Health Insurance Service for providing the insurance claims data.

\section{Authors' contributions}

JWS take full responsibility for the content of this manuscript, including its data and analysis. JWS. made substantial contributions to the conception and design of the study. HYY, JHK, Y.J.K, and JWS. made substantial contributions to analysis and interpretation of data. HYY, JHK, YJK, and JWS. drafted the initial manuscript. All authors discussed the results and reviewed, and finally approved the manuscript.

\section{Funding}

This study was supported by a grant from the Basic Science Research Program through the National Research Foundation of Korea (NRF) funded by the Ministry of Science, ICT, and Future Planning (NRF-

2016R1A2B4016318) and a grant (18-495) from the Asan Institute for Life Sciences, Asan Medical Center, Seoul, Korea. Funders had no role in study design, collection, analysis, interpretation of data, and in writing the manuscript.

\section{Availability of data and materials}

Any data generated and/or analysed during the current study are available from the corresponding author on reasonable request.

\section{Ethics approval and consent to participate}

The study was approved by the Institutional Review Board of Asan Medical Centre (2017-1190)

\section{Consent for publication}

Not applicable.

\section{Competing interests}

The authors declare that they have no competing interests.

\section{Author details}

'Division of Pulmonary and Critical Care Medicine, Department of Interna Medicine, College of Medicine, Ewha Woman's University, 25 Magokdong-ro 2-gil Gangseo-gu, Seoul 07804, Republic of Korea. ${ }^{2}$ Department of Pulmonary and Critical Care Medicine, Asan Medical Center, University of Ulsan College of Medicine, 88 Olympic-Ro 43-Gil, Songpa-Gu, Seoul 05505, Republic of Korea. ${ }^{3}$ Department of Clinical Epidemiology and Biostatistics, Asan Medical Center, University of Ulsan College of Medicine, 88 Olympic-Ro 43-Gil, Songpa-Gu, Seoul 05505, Republic of Korea.

Received: 30 April 2019 Accepted: 3 February 2020

Published online: 06 February 2020

\section{References}

1. Trapnell BC, Whitsett JA, Nakata K. Pulmonary alveolar proteinosis. N Engl Med. 2003;349(26):2527-39.

2. Seymour JF, Presneill JJ. Pulmonary alveolar proteinosis: progress in the first 44 years. Am J Respir Crit Care Med. 2002;166(2):215-35.

3. Ben-Dov I, Kishinevski Y, Roznman J, Soliman A, Bishara H, Zelligson E, Grief J, Mazar A, Perelman M, Vishnizer R. Pulmonary alveolar proteinosis in Israel: ethnic clustering. Isr Med Assoc J. 1999;1(2):75-8.

4. Inoue Y, Trapnell BC, Tazawa R, Arai T, Takada T, Hizawa N, Kasahara Y, Tatsumi K, Hojo M, Ichiwata T, et al. Characteristics of a large cohort of patients with autoimmune pulmonary alveolar Proteinosis in Japan. Am J Respir Crit Care Med. 2008;177(7):752-62.

5. Rosen SH, Castleman B, Liebow AA, Enzinger FM, Hunt RT. Pulmonary alveolar proteinosis. N Engl J Med. 1958;258(23):1123-42.

6. Slutzker B, Knoll HC, Ellis FE, Silverstone IA. Pulmonary alveolar proteinosis: case report and review of literature. Arch Intern Med. 1961;107(2):264-9.

7. Larson RK, Gordinier R. Pulmonary alveolar proteinosis: report of six cases, review of the literature, and formulation of a new theory. Ann Intern Med. 1965;62(2):292-312.

8. Du Bois R, McAllister W, Branthwaite M. Alveolar proteinosis: diagnosis and treatment over a 10-year period. Thorax. 1983;38(5):360-3.

9. Kariman K, Kylstra J, Spock A. Pulmonary alveolar proteinosis: prospective clinical experience in 23 patients for 15 years. Lung. 1984;162(1):223-31.

10. Prakash UB, Barham SS, Carpenter HA, Dines DE, Marsh HM. Pulmonary alveolar phospholipoproteinosis: experience with 34 cases and a review. Mayo Clin Proc. 1987;62(6):499-518.

11. McCarthy C, Avetisyan R, Carey BC, Chalk C, Trapnell BC. Prevalence and healthcare burden of pulmonary alveolar proteinosis. Orphanet J Rare Dis. 2018;13(1):129.

12. Byun MK, Kim DS, Kim YW, Chung MP, Shim JJ, Cha SI, Uh S-T, Park CS, Jeong $\mathrm{SH}$, Park YB. Clinical features and outcomes of idiopathic pulmonary alveolar proteinosis in Korean population. J Korean Med Sci. 2010;25(3):393-8.

13. Hwang JA, Song JH, Kim JH, Chung MP, Kim DS, Song JW, Kim YW, Cho SM, Cha SI, Uh ST, et al. Clinical significance of cigarette smoking and dust exposure in pulmonary alveolar proteinosis: a Korean national survey. BMC Pulmonary Med. 2017;17(1):147.

14. Kim HJ, Hann HJ, Hong SN, Kim KH, Ahn IM, Song JY, Lee SH, Ahn HS Incidence and natural course of inflammatory bowel disease in Korea, 20062012: a nationwide population-based study. Inflamm Bowel Dis. 2015;21(3): $623-30$

15. Park SJ, Kwon KE, Choi NK, Park KH, Woo SJ. Prevalence and Incidence of Exudative Age-Related Macular Degeneration in South Korea: A Nationwide Population-Based Study. Ophthalmology. 2015;122(10):2063-2070.e2061.

16. MS Y. Direction of policy and management for rare intractable disease patients support program [in Korean]. Health Insur Rev Assess Serv (HIRA) Policy Rev. 2009:3:6-10.

17. Ahn IM, Park DH, Hann HJ, Kim KH, Kim HJ, Ahn HS. Incidence, prevalence, and survival of moyamoya disease in Korea: a nationwide, population-based study. Stroke. 2014;45(4):1090-5.

18. Briens E, Delaval P, Mairesse MP, Valeyre D, Wallaert B, Lazor R, Cordier JF. Pulmonary alveolar proteinosis. Rev Mal Respir. 2002:19(2 Pt1):166-82.

19. Bonella F, Bauer PC, Griese M, Ohshimo S, Guzman J, Costabel U. Pulmonary alveolar proteinosis: new insights from a single-center cohort of 70 patients. Respir Med. 2011;105(12):1908-16.

20. Kim G, Lee SJ, Lee HP, Yoo CG, Han SK, Shim YS, Kim YW. The clinical characteristics of pulmonary alveolar proteinosis: experience at Seoul National University Hospital, and review of the literature. J Korean Med Sci. 1999;14(2):159-64 
21. Tian X, Luo J, Xu K-F, Wang L, Zhou J, Feng R, Gui Y, Wang J, Xu W, Xiao Y. Impaired lipid metabolism in idiopathic pulmonary alveolar proteinosis. Lipids Health Dis. 2011;10(1):54.

22. Ishibashi T, Yokoyama K, Shindo J, Hamazaki Y, Endo Y, Sato T, Takahashi S, Kawarabayasi Y, Shiomi M, Yamamoto T, et al. Potent cholesterol-lowering effect by human granulocyte-macrophage colony-stimulating factor in rabbits. Possible implications of enhancement of macrophage functions and an increase in mRNA for VLDL receptor. Arterioscler Thromb. 1994;14(10): 1534-41.

23. Sallese A, Suzuki T, McCarthy C, Bridges J, Filuta A, Arumugam P, Shima K, Ma Y, Wessendarp M, Black D, et al. Targeting cholesterol homeostasis in lung diseases. Sci Rep. 2017;7(1):10211.

24. Summers SA. Ceramides in insulin resistance and lipotoxicity. Prog Lipid Res. 2006:45(1):42-72.

25. Savage DB, Petersen KF, Shulman GI. Disordered lipid metabolism and the pathogenesis of insulin resistance. Physiol Rev. 2007;87(2):507-20.

26. Zhang D, Tian X, Feng R, Guo X, Wang P, Situ Y, Xiao Y, Xu KF. Secondary pulmonary alveolar proteinosis: a single-center retrospective study (a case series and literature review). BMC Pulmonary Med. 2018;18(1):15.

27. Pereira-Silva JL, Marinho MM, Veloso TV, Coelho JJ. Pulmonary alveolar proteinosis and tuberculosis in a diabetic patient: a rare or a seldom diagnosed association? Braz J Infect Dis. 2002;6(4):188-95.

28. Tekgül S, Bilaceroglu S, Ozkaya S, Coskun A, Komurcuoglu B, Cirak AK. Pulmonary alveolar proteinosis and superinfection with pulmonary tuberculosis in a case. Respir Med Case Rep. 2012;5:25-8.

29. Dragomir A, Ciontu M, Martius M, Munteanu I, Stoica R, Ulmeanu R, Serbescu A, Mihaltan F. Superinfection with mycobacterium tuberculosis in a patient with pulmonary alveolar proteinosis. Mædica J Clin Med. 2008;3(1):59.

30. Rothchild AC, Jayaraman P, Nunes-Alves C, Behar SM. iNKT cell production of GM-CSF controls mycobacterium tuberculosis. PLoS Pathog. 2014;10(1): e1003805.

31. Gonzalez-Juarrero M, Hattle JM, Izzo A, Junqueira-Kipnis AP, Shim TS, Trapnell BC, Cooper AM, Orme IM. Disruption of granulocyte macrophagecolony stimulating factor production in the lungs severely affects the ability of mice to control mycobacterium tuberculosis infection. J Leukoc Biol. 2005;77(6):914-22.

32. Ilkovich YM, Ariel BM, Novikova LN, Bazhanov AA, Dvorakovskaya IV, Ilkovich MM. Pulmonary alveolar proteinosis: a long way to correct diagnosis: problems of diagnostics and therapy in routine practice. Ann Clin Lab Sci. 2014;44(4):405-9.

\section{Publisher's Note}

Springer Nature remains neutral with regard to jurisdictional claims in published maps and institutional affiliations.

Ready to submit your research? Choose BMC and benefit from:

- fast, convenient online submission

- thorough peer review by experienced researchers in your field

- rapid publication on acceptance

- support for research data, including large and complex data types

- gold Open Access which fosters wider collaboration and increased citations

- maximum visibility for your research: over $100 \mathrm{M}$ website views per year

At $\mathrm{BMC}$, research is always in progress.

Learn more biomedcentral.com/submissions 